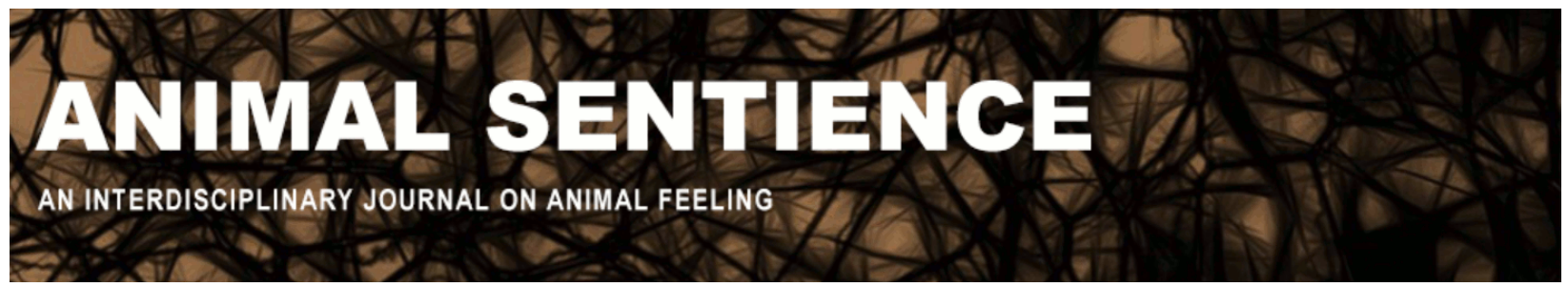

Brodbeck, David R. and Brodbeck, Madeleine I. R. (2017) Cognitive continuity in cognitive dissonance. Animal Sentience 12(8)

DOI: $10.51291 / 2377-7478.1269$

Date of submission: 2017-11-28

Date of acceptance: 2017-12-03

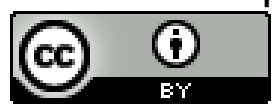

This article has appeared in the journal Animal

Sentience, a peer-reviewed journal on animal

cognition and feeling. It has been made open access,

free for all, by WellBeing International and deposited

in the WBI Studies Repository. For more information,

please contact

wbisr-info@wellbeingintl.org.

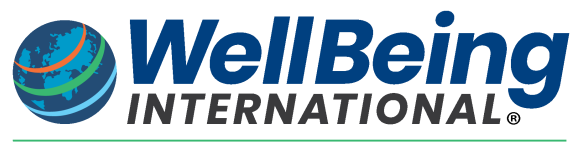

SOLUTIONS FOR PEOPLE, ANIMALS AND ENVIRONMENT 


\title{
Cognitive continuity in cognitive dissonance
}

\author{
Commentary on Zentall on Cognitive Dissonance
}

\author{
David R. Brodbeck \\ Department of Psychology \\ Algoma University \\ Madeleine I. R. Brodbeck \\ Department of Psychology \\ University of Western Ontario
}

\begin{abstract}
Zentall's (2016) model of cognitive dissonance is compatible with cognitive continuity between humans and nonhumans. It may help explain cognitive dissonance-like behavior in many species, including humans. It is also consistent with Tinbergen's (1963) 'four whys' in ethological explanation.
\end{abstract}

David R. Brodbeck is an associate professor of psychology at Algoma University in Sault Ste. Marie, ON, Canada. His work focusses on the evolution of cognition, especially spatial memory. Brodbeck also hosts the animal cognition podcast 'Spit and Twitches'. www.davebrodbeck.com

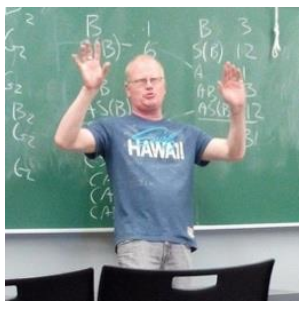

Madeleine I. R. Brodbeck is a PhD student in psychology at the University of Western Ontario in London, ON, Canada. Her work focusses on the role of the avian hippocampus in encoding, retention and retrieval of spatial memory.

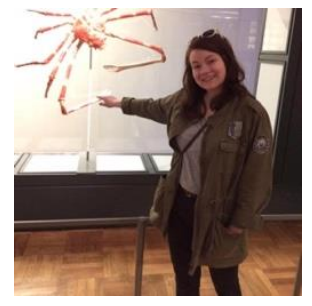

Zentall (2016) lays out a rather compelling case for explaining cognitive dissonance with a model that relies not on conscious control of behavior but on reinforcement and standard animal cognition approaches. The model may not necessarily satisfy those who are interested in conscious control of behavior in non-humans, but it is parsimonious and it also follows a standard approach used in biology. It does not imply that non-humans don't experience dissonance in some fashion similar to humans, or that they do. It is quite possible that similar mechanisms are preserved in humans.

Tinbergen (1963) laid out his famous 'four whys' to be answered if one is to fully understand any characteristic, including behavior. These include two proximate causes, ontogeny and mechanism, and two ultimate causes, the evolutionary history of the characteristic and its adaptive value. As MacDougall-Shackelton (2011) points out, these are not competing explanations of a behavior. Although the word 'ultimate' seems to imply that such explanations 
are better than proximate ones, this is not the case. Confusion about this has led to much nonproductive debate. In explaining migration in birds functionally, in terms of the need to get to a warmer climate, MacDougall-Shackelton does not compete with the mechanistic explanation that circulating hormones induce migratory restlessness. Both explanations are correct, despite the fact that they take different perspectives; and both expand our knowledge of migration.

In human cognitive dissonance, there is not only an internal mechanism, but there is also the phenomenological aspect of self-justification. Zentall uses an excellent example about cigarette smokers to explain cognitive dissonance. Many psychoactive drugs have this paradoxical effect. We imagine more than one reader has had the experience of drinking too much alcohol and awaking the next day vowing never to drink again. Then, later that same day, they drink alcohol. They may justify these conflicting thoughts by rationalizing that they will only have one drink, or that they are just going to a bar to be social with friends, but this is what psychologists call cognitive dissonance.

Why then do people drink to excess or smoke cigarettes? Ingestion of psychoactive substances is physiologically rewarding. The mesolimbic dopamine system is activated whenever we do something pleasurable (Hancock \& McKim, 2017): people develop smoking habits because it feels good. This is a mechanism for the cognitive dissonance associated with taking drugs.

The mechanistic account of cognitive dissonance may be something similar to Zentall's (2016) model. What is the functional or adaptive explanation of the phenomenon? Animals, including humans, are susceptible to the 'Concorde fallacy'. They tend to reason (fallaciously) that investing a high amount of effort makes sunk costs more valuable (Curio, 1987). Past effort could be used as a rule of thumb by foraging animals. They may 'believe' that something in which they have put a lot of effort is actually worth it because it often is (Kacelnik \& Marsh, 2002).

It would be adaptive for humans to have an additional mechanism along with the rule of thumb. Whereas most of our cognition is inaccessible to consciousness, some of it is (Schacter, 1987). Evolution may have selected for individuals who self-justify putting greater amounts of effort into foraging, for example. Such an approach to foraging could have been adaptive in the ancestral environment of evolutionary adaptation (EEA), but we don't live in the EEA. So today we see only the deleterious effects of cognitive dissonance.

The non-human data that Zentall (2016) describes appear to resemble cognitive dissonance in humans. There may even be a phenomenological aspect to pigeon cognition, although this is something we cannot know. When behavior has inputs and outputs similar to those of human behavior, it is tempting to give the phenomenon the same name (e.g., Brodbeck, 1997, Shettleworth, 2012).

Zentall's approach is consistent with the findings on cognitive dissonance in humans. An extra conscious mechanism (the self-justification aspect of cognitive dissonance) was selected for during our species's evolutionary past. Some nonhuman species may also have a similar mechanism. Hence Zentall's explanation is compatible with cognitive continuity between humans and non-humans in this phenomenon (e.g., Shettelworth, 2010). 


\section{References}

Brodbeck, D. R. (1997). Picture fragment completion: Priming in the pigeon. Journal of Experimental Psychology: Animal Behavior Processes, 23(4), 461-468.

Curio, E. (1987). Animal decision making and the Concorde fallacy. Trends in Ecology and Evolution, 2(6), 148-152.

Hancock, S. \& McKim, W. (2017). Drugs and Behavior: An Introduction to Behavioral Pharmacology ( $8^{\text {th }}$ Edition). Pearson.

Kacelnik, A. \& Marsh, B. (2002). Cost can increase preference in starlings. Animal Behaviour, 2(63), 245-250.

MacDougall-Shackelton, S. (2011) The levels of analysis revisited. Philosophical Transactions of the Royal Society of London, B, Biological Sciences, 36(1574), 2076-2085.

Schacter, D. L. (1987). Implicit memory: History and current status. Journal of Experimental Psychology: Learning, Memory \& Cognition, 13(3), 501-518.

Shettleworth, S. J. (2010). Clever animals and killjoy explanations in comparative psychology. Trend in Cognitive Science, 14(11), 477-481.

Shettleworth, S. J. (2012). Do animals have insight, and what is insight anyway? Canadian Journal of Experimental Psychology, 66(4), 217-226.

Tinbergen, N. (1963). On aims and methods of ethology. Zeitschrift für Tierpsychologie, 20(4), 410-433

Zentall, T. R. (2016). Cognitive dissonance or contrast? Animal Sentience 12(1). 